\title{
Endoscopic management of postesophagectomy leak with modified clip-and-loop technique
}

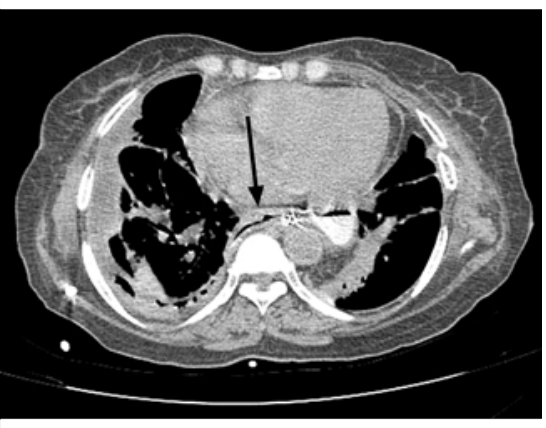

- Fig. 1 Computed tomogram of the chest showing leakage from the anastomotic site (arrow).

A 75-year-old woman with carcinoma of the lower esophagus underwent esophagectomy with proximal gastrectomy. On the 6th day after surgery, she developed breathlessness with chest pain and highgrade fever. Computed tomography (CT) of the chest showed a leak from the anastomotic site tracking into the right pleura (\$Fig.1). Upper gastrointestinal endoscopy showed dehiscence of approximately $1 \mathrm{~cm}$ at the anastomotic site ( Fig.2). After multidisciplinary discussion, endoscopic rent closure was planned. The edges of the defect were ablated using argon plasma coagulation. Due to angulation, complete apposition of the defect using clips was not feasible. Resolution clips (Boston Scientific, Marlborough, Massachusetts, USA) were applied to the edges of the defect. An endoloop (Olympus Medical, Tokyo, Japan) was applied to tie the clips together to close the defect completely ( Video 1 ) ( Fig.3). There was a decrease in the right pleural drain output, with contrast swallow showing no leak on day 5 ( Fig.4). Repeat endoscopy on day 14 showed a completely healed defect at the anastomotic site ( $>$ Fig. 5 ).

The "loop clip" technique for closure of defects after endoscopic submucosal dissection was initially described by Sakamoto et al. in 2008, where a loop is attached to the edges of a defect with

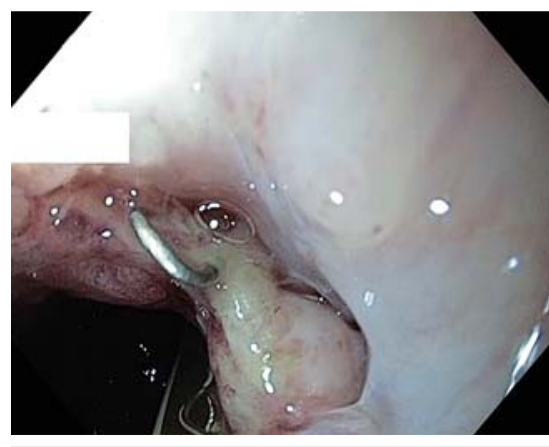

- Fig. 2 Upper gastrointestinal endoscopy showing dehiscence at the anastomotic site, approx. $1 \mathrm{~cm}$ in size.

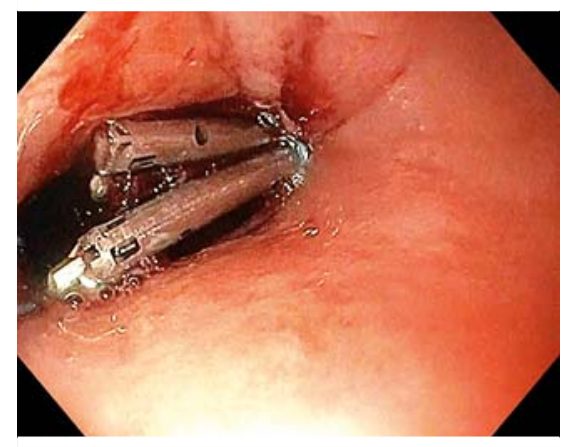

- Fig. 3 Defect closed completely using a modified clip-and-loop technique.

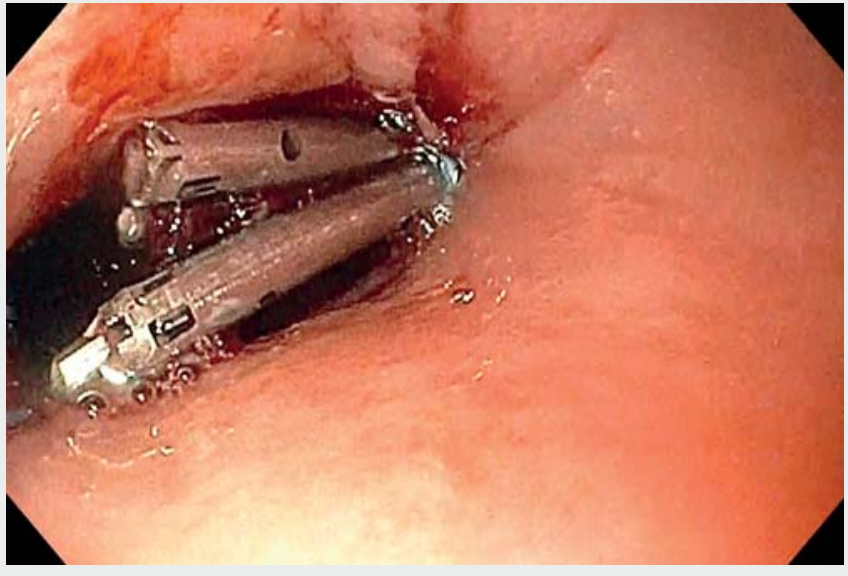

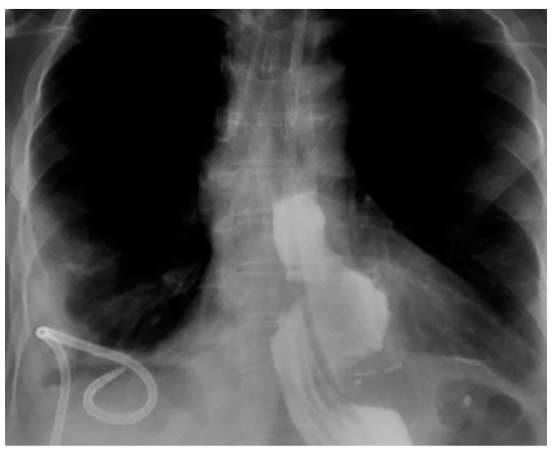

Fig. 4 Contrast swallow on day 5 showed no leak.

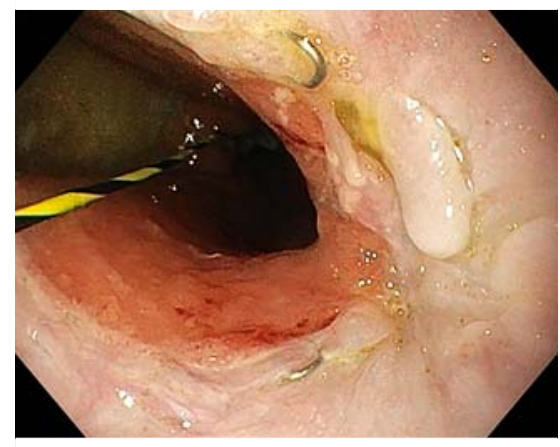

> Fig. 5 Completely healed defect at the anastomotic site on day 14 . 
clips and subsequently tightened to close the defect [1,2]. Other techniques that have been described for gastrotomy closure are the King technique and Queen technique [3,4], in which a double-channel endoscope or multiple loops are required. The modified clip-and-loop technique we used has been described by Luigiano et al. for closure of tracheoesophageal fistula [5]. In our patient the size of the defect was small, making it difficult to attach a loop to the edges of the defect. Complete closure using clips was difficult due to the angulation and free lower edge. Hence the clips were tied together to ensure approximation and complete closure of the defect.

Endoscopy_UCTN_Code_TTT_1AO_2AI

\section{Competing interests}

The authors declare that they have no conflict of interest.

The authors

Sridhar Sundaram ${ }^{1}$, Raosaheb Rathod ${ }^{1}$, Utkarsh Chhanchure ${ }^{1}$, Prachi Patil ${ }^{1}$, Kiran Mane ${ }^{1}$, Devayani Niyogi ${ }^{2}$, Shaesta Mehta

1 Department of Digestive Diseases and Clinical Nutrition, Tata Memorial Hospital, Mumbai, India

2 Department of Surgical Oncology, Tata Memorial Hospital, Mumbai, India
Corresponding author

Sridhar Sundaram, MD, DM

Department of Digestive Diseases and Clinical Nutrition, Tata Memorial Hospital, Homi Bhabha National Institute, Dr. E Borges Road, Parel, Mumbai 400012, India

drsridharsundaram@gmail.com

\section{References}

[1] Sakamoto N, Beppu K, Matsumoto K et al. "Loop Clip", a new closure device for large mucosal defects after EMR and ESD. Endoscopy 2008; 40: E97-E98

[2] Nomura T, Kobayashi M, Morikawa T et al. Clip-fixed endoloop: an efficacious new method for mucosal defect closure. Endoscopy 2018; 50: E126-E127

[3] Hookey LC, Khokhotva V, Bielawska B et al. The Queen's closure: a novel technique for closure of endoscopic gastrotomy for natural-orifice transluminal endoscopic surgery. Endoscopy 2009; 41: 149-153

[4] Ryska O, Martinek J, Filipkova T et al. Single loop-and-clips technique (KING closure) for gastrotomy closure after transgastric ovariectomy: a survival experiment. Wideochir Inne Tech Maloinwazyjne 2012; 7: 233-239

[5] Luigiano C, Ferrara F, Polifemo AM et al. Endoscopic closure of esophageal fistula using a novel "clips and loop" method. Endoscopy 2009; 41: E249-E250
Bibliography

Endoscopy 2022; 54: E488-E489

Dol 10.1055/a-1638-8657

ISSN 0013-726X

published online 8.10 .2021

(c) 2021. Thieme. All rights reserved.

Georg Thieme Verlag KG, Rüdigerstraße 14,

70469 Stuttgart, Germany

ENDOSCOPY E-VIDEOS

https://eref.thieme.de/e-videos

回的 Endoscopy E-Videos is an open access online section, 自触: reporting on interesting cases and new techniques in gastroenterological endoscopy. All papers include a high quality video and all contributions are freely accessible online. Processing charges apply (currently EUR 375), discounts and wavers acc. to HINARI are available.

This section has its own submission website at https://mc.manuscriptcentral.com/e-videos 